\title{
Cooperation in the Spanish Banking Industry: Factors Determining Value Creation
}

\author{
Nuria Alcalde*, Manuel Espitia, Nieves García \\ Department of Business Administration, University of Zaragoza, Spain
}

\begin{abstract}
In the current work we consider the question of whether the differential benefits obtained by listed Spanish banks from their participation in alliances in the period 1996-1999 depend on the conditions under which these occur. From the results obtained we deduce that value generation is significantly greater when a bank announces an alliance with related partners, and in addition has an important previous experience in alliance management. However, the market reacts negatively to the announcement of agreements that use a relatively non-hierarchical governance structure in the presence of a high level of transaction complexity.
\end{abstract}

Keywords Cooperation, Value Creation, Event Studies, Transaction Costs, Spanish Banks

\section{Introduction}

Studies analyzing the result of alliances have received less attention than other areas within the study of cooperation agreements, due to the obstacles of this type of research, among which of course we find measuring the result of the alliance as well as the difficulties in gathering the necessary data for carrying out such a valuation. Although the results of alliances have been measured using various approaches, many authors consider that a key aspect for its study is analyzing the consequences on the results of the partner firms, or the value generation, when these form part of cooperation agreements $[1,2]$.

Within this group of work, many researchers used as proxy the variation seen in the capital market of the share prices of the firms participating in the alliance, using for this the event study methodology [3]. But past research not only centers on analyzing the reaction of the stock market to the formation of alliances in order to determine if there is value creation for these firms' shareholders. Researchers have also examined the excess returns that these firms receive for entering different types of alliance and how these are influenced by the conditions under which the alliances have been formed [1].

According to Madhok and Tallman [4], there are two factors determining the value generated by an alliance: on the one hand, the rents that derive from combining the resources of the firms in collaboration; and on the other, the costs associated with carrying out the transactions by means of an alliance.

Although there are various sources of potential rents from cooperation, these can basically be grouped into two categories. First, the firms agreeing to cooperate can benefit from a greater efficiency in carrying out their activities, as a consequence of gaining access to complementary resources, obtaining economies of scale or scope, or risk reduction. Second, cooperation is a strategy that can allow firms to collude and thereby achieve greater market power.

With respect to the potential costs of cooperation between firms, these can be classified into coordination costs and motivation costs. Thus, on the one hand, a constant coordination is necessary between the parties in order for the objectives sought to be achieved, and on the other, there is a need to avoid the risks deriving from the potentially opportunistic behavior of one or other of the partners.

Although the combination of potential benefits and costs and their valuation vary according to the particular characteristics of each agreement, from a rational point of view firms will only decide to cooperate when they perceive that the potential benefits exceed the potential costs and that therefore a positive net value can be generated by cooperating. From this perspective then, it is coherent that the majority of empirical studies carried out find that cooperation agreements do indeed generate value $[5,6,7,8,9,10,11]$.

However, we would not expect all cooperation strategies to generate the same value. Thus, the value generated should be positively affected, on the one hand, when there are a series of characteristics permitting the potential benefits of the cooperation to be achieved more easily; and on the other, when the most appropriate governance structure is chosen in order to minimize transaction costs.

Various studies suggest that a greater degree of relation between the partners' activities [1,5], more experience in alliance management $[12,13]$ or a greater degree of relation between the activities of the partner and those of the alliance $[2,14]$, positively influence value generation. These are undoubtedly aspects permitting the potential benefits of the cooperation (efficiency or market power) to be achieved more easily. However, these benefits can be offset by higher 
costs if the form of governance selected is not optimal.

From the transaction cost economics approach, cooperation agreements are considered to be hybrid governance structures somewhere between the firm and the market. However, within the continuum of possible organizational alternatives regulating exchanges made up by cooperation agreements, there is a wide variety of governance structures sufficiently differentiated among themselves. The correct choice is significant, given that the management of the transaction will be more efficient when there is an alignment or correspondence between the governance structure chosen and the fundamental attributes of the transaction [15].

Various empirical studies, mainly using the arguments of transaction cost economics, try to explain the choice between various modes of inter-firm cooperation by considering the observable characteristics of the corresponding transactions $[16,17,18]$. With respect to the influence that an appropriate choice of alliance governance structure has on its results, in Sampson's [19] work on R\&D agreements the author concludes that choosing the wrong governance structure for the alliance negatively affects the results, measured in terms of the number of patents achieved. However, we have not been able to find any empirical studies analyzing the impact of the correct or incorrect choice of governance structure on the value generated by cooperation agreements.

In this respect, the objective of the current research is to analyze the influence on value generation in cooperation agreements of those factors affecting the potentially achievable rents (relation between the partners' activities, relation between the partner's activities and those of the alliance and previous experience in alliance management), as well as the (in)appropriate choice of governance structure permitting (or otherwise) the firms to achieve these potential benefits at the same time as minimizing transaction costs.

The sector chosen for our research is the Spanish banking sector, specifically those banks listed on the Madrid stock exchange during the period 1996 to 1999 . This choice is justified in view of the fact that during this period Spanish firms had to adapt its strategies to compete in a new environment (the EMU) using alliances for this purpose. Banking sector was one of the most prolific in its use of alliances and at the same time, it has not been the object of specific empirical research on value creation in alliances for the Spanish case.

The work is structured as follows: first, we formulate the hypotheses, with the aim of identifying the factors that potentially determine value creation in alliances. Next, and in the framework of transaction cost economics, we defend the theoretical foundations supporting the decisions about the choice of governance structure; at the same time we discuss some of the variables that may affect the probability that an alliance is formalized using a particular governance structure. After presenting the design of the research (the characteristics of the sample used, the event study methodology and the variable measurement), in the fifth section we discuss our main findings. The work ends with a conclusions section, where we summarize the main contributions and limitations of our work.

\section{Theoretical Discussion and Formulation of the Hypotheses}

Although we cannot deny that some firms use agreements with collusive ends ${ }^{\mathrm{i}}$ - in fact in this respect cooperation agreements are a means by which firms can directly affect competition through aspects such as the erection of entry barriers or increasing market concentration [20] - Jacquemin [21] considers that cooperation agreements are equally likely to lead to a series of important competitive effects, thanks to the exploitation of complementarities and synergies, among other factors.

Thus, the fear of competitive rivalry encourages many firms to form alliances to mitigate the competition. But cooperation not only permits firms forming part of the alliance to achieve market power: it is also recommendable when they seek particular resources that are complementary to those now held [22]. This can help the firm to achieve synergies [23], although these are always potential and it is up to the firm to realize them.

In short, both with the search for market power (with its possible anti-competitive effect) and with the reaping of synergies, alliances can potentially generate value.

On the other hand, selecting the optimal governance structure to manage the alliance will increase its efficiency, such that the potential benefits mentioned above can be achieved with minimum costs. In contrast, an incorrect choice of governance structure will generate unnecessary costs and therefore one would expect it to negatively influence investors' expectations.

We now propose four hypotheses concerning the influence on value generation in alliances of those factors allowing the generation of synergies or market power, as well as of the error in the choice of the optimal governance structure.

In an environment such as the banking sector - subject in recent decades to profound changes - combining resources successfully will depend on the existing interrelation between the resources of the participating firms. But it is true that not all combinations of resources and capabilities are equally effective. In fact, the partners will be better able to make their resources work together in the search for economic benefits when they are related.

Since the firm does not have everything it needs to succeed, one would expect the market to react positively when the firm seeks complementary resources, since they will allow it to grow without having to take on all the investment alone.

In turn, the similarity between the partners' activities will lead to gains in efficiency for the firms participating in alliances, since it facilitates communication between the alliance partners. This reduces the information asymmetries between them, allowing a prompt detection of any opportunism that arises [24]. 
Furthermore, there will be fewer incentives for opportunistic behavior for partners operating in the same product-market binomial in an environment such as the Spanish market, characterized by a relatively large number of potential partners, since the process of consolidation in the banking sector in Spain is still under way at present. This allows firms to choose partners avoiding those who have previously exhibited opportunistic behaviors [17], and to easily find a new partner [25] should their current one behaves opportunistically.

When the partners are active in different businesses, it is difficult to predict all the contingencies that may arise as a consequence of the cooperation, making it difficult to write complete contracts, so that certain points will be left pending for future negotiations. Moreover, the problem is worsened when the information accumulated by the partners is asymmetric, which is particularly likely when each party takes responsibility for different tasks, such as in the case of vertical-type cooperation.

Thus, when the partners belong to related businesses, there may well be gains associated with greater efficiency and market power, as well as more opportunities to reap synergies.

Hypothesis 1: Cooperation agreements with partners operating in related activities generate more value for the bank partner than those formed with firms working in non-related activities.

As well as the coincidence between the activities of the partners, a close relation between the businesses of the partner and those of the alliance will also favor enhanced operative efficiency as well as increased market power.

When all the partners are close to the activity of the alliance, the resources and capabilities brought in by the partners will complement each other, allowing the alliance to fulfill the objectives for which it was designed sufficiently quickly for the demands of the evolving environment, which will ultimately have repercussions in the market's valuation of the alliance. If, in contrast, not all partners have the same relation with the businesses of the alliance, one would expect that the related partner or partners would start from a more favorable position than the others in terms of their possibilities of obtaining gains from the cooperation [2,14], since they will be better able to coordinate the activities of the alliance with their own strategic objectives [26]. Thus, when banks form alliances to carry out financial activities, alongside the existence of private objectives in these firms a new calendar of common objectives will develop, which will occasionally have positive repercussions on the private objectives. Hence the expectations of benefit will improve, and with them the potential for value creation. Furthermore, for the bank partner related with the activity of the alliance, starting an alliance will mean a reduction in the uncertainty and hence less chance of overvaluing or undervaluing the targeted resources [10], so that this type of alliance will be positively perceived as it presents no information asymmetries.

Hypothesis 2: The value generation for the bank's shareholders will be greater if the main activity of the alliance is financial.

Firms participating in cooperation agreements will try to exploit the knowledge transferred from their partners, not only to improve the activities of the alliance itself, but also their own activities, to the extent that they are able to assimilate the new knowledge as their own [27].

Furthermore, even if we accept that the capacity of learning through cooperation is specific to the partner [28] and that the experience effect is tacit knowledge [29] that is difficult to formalize [30], we can assume the existence of a learning curve in alliance management [31], which allows firms to improve their performance by means of repetition and the accumulation of experience.

Thus, experience in alliance management ${ }^{\mathrm{ii}}$ allows firms to learn the cooperation process itself, resulting in an improvement in its management [32]. Hence, those organizations that are able to institutionalize it will be better able to specify and manage the activities of the alliance.

From another perspective, possessing previous experience of alliance management may provide an incentive for the firm to commit itself to a more correct behavior [19], which generates trust in potential alliance partners, and this trust, in turn, limits the transaction costs associated with the new alliance [33]. When a partner enters an alliance with another partner that has already participated in a large number of alliances, we can say that the participants are taking calculated risks [34], because they have high expectations that their partners will behave responsibly.

Moreover, the experience of previous cooperation also means that future cooperation become more predictable. In this respect, and since alliances are organizational forms in which it is not easy to establish beforehand all the contingencies that may arise, we would expect that a greater experience in alliance management allows firms to generate sufficient skills to anticipate possible contingencies which can arise in a new alliance, in order to respond to them more effectively [12] and to resolve any conflicts that surface [35].

Hypothesis 3: Value generation for the bank partner will be greater when it possesses previous experience in alliance creation.

Just as researchers attempt to explain why the market or the firm are used as alternative governance mechanisms for economic transactions, we can also ask why firms choose different forms of governance for their collaborations [36], especially when in some cases the collaboration is supported more on market principles while in others it incorporates principles characteristic of the hierarchy. In any case, firms adopt a wide variety of agreements to formalize their alliances [37,38].

The complexity of the transaction will condition the choice of the optimal governance form for the alliance [39]. 
Complexity is in turn defined as a growing function whose attributes are identified as a source of transaction costs [36].

Thus, as complexity rises we would expect the forms of collective action containing a strong presence of authority, such as is the case in joint ventures, to predominate [39], since according to transaction cost economics $[15,40]$ they should generate lower transaction costs than other forms of alliance governance closer to the market. Both creating a new firm owned by the partners and firms' direct participation in the equity of their partners are forms of participation that protect investments - especially if specific capital is involved - reduce the problem of moral hazard and possible opportunistic behaviors by aligning the partners' incentives, and reduce ex-post opportunism in the distribution of the resulting surplus. In short, they attenuate everything that can be associated with the presence of uncertainty.

Alliances with governance structures closer to the market have, in turn, low starting up costs. These costs increase however when complexity grows for any particular reason, because of the difficulty in anticipating all the contingencies that may arise. Thus, having chosen an alliance structure close to the market, if the agreement becomes more complex this may lead to a misfit which becomes a source of inefficiencies. Similarly, the presence of complexity would tend to recommend the joint venture form. However, if aspects that were not previously contemplated surface - such as the need for investment in specific human capital ${ }^{\text {iii }}$ - the costs of this form of governance rise, which again leads to a misalignment.

Thus, we establish the following hypothesis, which continues, in part, the empirical research of Pisano [17] and Hennart [41], and which postulates that the form of governance chosen to govern the cooperation may not always be the most efficient, in which case the market perceives greater transaction costs. The market will respond by penalizing the value creation of the alliance.

Hypothesis 4: The generation of value for the bank partner is negatively related to the error in the choice of contractual form.

\section{Alliance Governance Structure and Transaction Costs}

Transaction cost theory has been one of the dominant paradigms used in the study of alliances. Indeed, many authors who have been interested in the structures used in alliances in recent years have adopted a theoretical position based on transaction costs $[42,17]$. According to this theory, no form of transaction governance is superior or inferior to any other per se, so that Williamson's [15] model, which guides the firm's choice between externalizing the transaction, internalizing it or hybrid forms, acts by taking into consideration allocative efficiency.

From transaction cost economics, scholars have also examined the factors explaining the choice of governance structure [16,17]. In this current work, we consider that the type of governance structure used in the formation of an alliance will either be close to that of the market or to the hierarchy, depending on the amount of transaction costs. Thus, the greater the transaction costs, the more hierarchical elements the contracts will have, while the lower the transaction costs, the closer the contractual agreements will be to the price system. In this respect, the sources of transaction costs will be the opportunistic behaviors of the partners, the specific investment in and/or for the alliance, or the uncertainty associated with the cooperation in itself, among others.

Earlier research in transaction cost economics has classified the governance structures of alliances in function of the use or otherwise of direct investment in the equity $[16,43,17]$. Alliances that involve direct investment in the equity can take the form of the joint venture, which involves the creation of a new entity independent of the partners. Alternatively, the partners can take cross or individual shareholdings in the equity of one or other of the partners $[42,44]$. Non-equity agreements, in turn, do not involve sharing or exchanging equity, and include sub-contracting, licenses, distribution agreements, exchange of technology, etc. Thus, equity-based alliances, as we have mentioned, are considered to be closer to the hierarchy form, because they involve a larger number of hierarchical elements, while those that do not are closer to the market. The justification provided by transaction cost theory is that the use of equity alliances suggests the presence of transaction costs that are so high that quasi-market structures are not recommended. In this respect, both Pisano [17] and Gulati [16] defend partial ownership, since this: improves the coordination of the alliance, above all, when an independent entity is created; permits hierarchical supervision, especially when the partners participate in the board of directors of the partner or partners that have received the investment, thereby reducing the costs associated with the presence of asymmetric information. At the same time, partial ownership limits the possibility of opportunistic behaviors in the course of the alliance [25]. In contrast, in this type of alliance there are costs associated with a longer period of negotiation, greater costs for leaving the alliance as well as higher management costs.

Similar arguments, but in the opposite sense, could be used when evaluating alliances that do not involve investment in equity. Thus, in this type of alliance there are savings in costs as a consequence of the rapid negotiation. However, these agreements are more vulnerable to opportunistic behaviors on the part of the partners, especially when it is tacit knowledge that is transferred, which in turn discourages investment in specific assets in the alliance, due in part to the difficulty of specifying the property rights precisely.

In order to measure the degree of alignment between the governance structure of the alliance chosen by the firm and the attributes of the alliance, we used, following Reuer \& Ariño [45], a model of governance structure choice which 
relates the governance structure with the characteristics of the transaction.

From this point we examine the factors explaining the propensity to use one or other of the governance structures proposed. For this, we use as explanatory variables the attributes of the transaction that are sources of complexity: the nature of the relationships between the firms cooperating, the number of projects (activities) involved in the alliance, the type of activity for which it is created, the geographical and cultural distance between the partners, the geographical scope of the alliance, the previous experience in managing alliances, the number of partners involved and the purpose of the cooperation.

The nature of the relationships between the firms cooperating. When the partner is active in a different sector from that of the firm in which it takes a share of the equity and hence giving it the right to a position on the board of directors - the board must deal with a wide range of subjects, of which only some will be directly related to the collaboration [17], raising the transaction costs unnecessarily. In contrast, when the partners belong to related businesses, a position on the board will allow the partners to resolve conflicts, exchange strategic information and take opportune decisions in the face of unexpected contingencies. If moreover the firms that decide to enter the alliance are direct competitors, it is always possible that among the many objectives of the alliance is the desire to increase market power, although for such power to be effective the firms must establish long-term links through investment in the equity.

The field of application of the alliance. Collaborations involving many projects also increase the number of contingencies that must be considered in the initial agreement [17]. Including many activities is a source of complexity for the agreement and hence complicates the management of the alliance, as well as making it less likely to be able to predict all the contingencies that may arise during the course of the relationship. Thus, we would expect that when the collaboration is designed to carry out a single activity, the use of structures closer to the price mechanism is more likely, while when the agreement involves many activities, the use of equity agreements is more probable $[18,39]$.

The type of activity for which the alliance is created. If the cooperation is formalized to continue the financial activity of the bank partner, we would expect there to be transfers of tacit knowledge to the alliance, which is always difficult to protect, so that this will be an attribute increasing the complexity and hence the need to introduce hierarchical elements into the agreement. However, and for this same case, we could also argue that when the activities of the partner are related to those of the alliance, the bank partner has less need for co-ordination with the other partners, since the activity carried out in the alliance is part of the business it controls. This would therefore cut the transaction costs.

The geographical and cultural distance between the partners. If the partners are domestic, the cultural proximity is closer and hence there is less need for the agreement to consider all the contingencies that may arise. Foreign partners, for their part, introduce more complexity into the transaction, in part because of the difficulty of establishing continuing contact with them in order to improve the terms of the relationship, and in part because of the greater difficulty in keeping track of the relationship, so that in this case there is a tendency to incur more short-term costs in order to avoid ex-post costs. Accordingly, we would expect equity alliances to be more likely among partners of different nationalities.

The geographical scope of the alliance. Alliances locating their activities outside the bank partner's country involve more uncertainty with respect to cultural, linguistic or even political aspects, so that they will more likely incur higher transaction costs than those located domestically. Thus, we would expect that when the geographical scope of the alliance goes beyond the limits of the partner's country, the agreements will be organized by means of equity-based structures.

Previous experience in cooperation is a source of complexity reduction in the transaction, since firms that repeatedly cooperate transmit cooperative behavior to their partners, thereby improving their reputation. This in turn makes it less likely that the firm will behave opportunistically and incentivises recurring transactions between the same partners. Thus, a cooperative reputation will lead to the setting-up of transaction governance structures closer to the market, since the trust generated will allow partners to replace hierarchical elements by numerous exchanges and acts as a mechanism facilitating future agreements.

Alliances can be between two or more partners. Increasing the number of partners in collaboration increases the likelihood that dysfunctions will arise within the group, and hence increases the need for co-ordination, as there are more interactions between the partners. As the number of partners increases there is also a need for more resources for evaluating the individual contributions of each partner in favor of the group, which facilitates the appearance of opportunistic behaviors, an attribute which raises the complexity of the transaction. In general, we consider that problems and organizational conflicts are more likely to appear in multilateral than in bilateral alliances, so that we would expect cooperation in the former to be governed by an equity-based structure.

All the above allows us to affirm that in the presence of high levels of attributes lending complexity to the transaction, we would expect the partners of the cooperation to use a formula of collective action close to that of the firm, while when the attributes indicate a low level of complexity in the transaction the partners would choose forms of governance close to that of the market. In order to detect the possible deviations with respect to the ideal form that should operate in each case, we propose to obtain an estimate of the most efficient cooperation option in each case and compare this with the option actually chosen. According to this approach, 
therefore, we do not analyze the misfits that may derive from using a contractual agreement for governing transactions that should ideally be managed via the market, nor the misfits deriving from the use of equity agreements for governing transactions that would be more efficient when internalized in the firm. However, as Sampson [19] points out, it is easier for firms to choose appropriately between organizational forms as differentiated as the market, the firm or a hybrid structure, with errors of choice much more likely when choosing between the much less differentiated forms within each of the three broad categories.

\section{Materials and Methods}

\subsection{Sample Composition and Characteristics}

The sample used in this work comprises 465 announcements of cooperation agreements, appearing in the press in the period 1996-1999, in which at least one of the firms taking part in the alliance was a bank listed on the Madrid stock exchange during the period of interest and for which daily share price information is available. Thus, the unit of analysis used for this research is the alliance announcement by at least one of the listed banks.

The choice of the period is justified by the fact that during these years Spanish firms had to adapt its strategies to compete in a new environment (the EMU and the official launch of the euro in 1999) and this lead to the creation of a large number of alliances.

We have used secondary sources to build our database. Specifically, the sample used has been built using the articles database "Baratz", containing economic news from the main Spanish dailies as well as general information and specialized magazines. Initially, we identified 674 announcements of cooperation agreements in which at least one bank listed on the Madrid stock exchange participated. However, this preliminary sample was refined using the criteria presented in Table 1.

Table 1. Description of Process of Obtaining Sample

Announcements

\begin{tabular}{ccc}
\hline & $\begin{array}{c}\text { Announcements of agreements with participation } \\
\text { by a bank for period 1996-1999. }\end{array}$ & 674 \\
$-\quad \begin{array}{c}\text { Announcements contaminated by other } \\
\text { announcements in event window [-1,+1]. }\end{array}$ & 195 \\
Announcements by banks with thinly-traded stock, \\
of which we do not have the abnormal returns in \\
day 0.
\end{tabular}

Thus, as we can see from Table 1, we have eliminated 209 announcements, so that the sample finally used is composed of 465 agreement announcements (408 different alliances) involving a total of 22 listed banks.

\subsection{Methodology}

The methodology applied in this work to quantify the value generated for the bank partner in the formation of an alliance is known as the event study methodology.

Event studies are based on the assumption of the rational behavior of the capital markets, or in other words, of their information efficiency. A firm's share price accurately reflects the expectations of investors with regards the firm's efficiency and profitability in the long term. Any public information that affects the value of the firm will immediately be incorporated into the price of the security by the market. Thus, by analyzing the evolution of the share price performance of firms in a brief period around the date of the announcement of the event, and by appropriately isolating other factors, we can measure the influence of the event in question on the value of these firms.

Applying this methodology, the abnormal return of a security $i$ on day $t\left(A R_{i t}\right)$ is obtained as the difference between its observed return $\left(R_{i t}\right)$ and the normal return. The latter is defined as the return that would have been expected if the event had not occurred $\left(E\left[R_{i t}\right]\right)$. In this way we wish to isolate that part of the observed return due exclusively to the announcement of the event.

$$
A R_{i t}=R_{i t}-E\left[R_{i t}\right]
$$

The model used in the present work to calculate the expected return of security $i$ on day $t^{\mathrm{iv}}$ is the single-factor market model with daily returns ${ }^{\mathrm{v}}$. This model establishes a linear relation between the return of each security and the market return $\left(R_{m t}\right)$ [46].

$$
\widetilde{R}_{i t}=\alpha_{i}+\beta_{i} \widetilde{R}_{m t}+\widetilde{\varepsilon}_{i t}
$$

Having obtained the OLS estimations of the model parameters $\hat{\alpha}_{i}$ y $\hat{\beta}_{\mathrm{i}}$, the abnormal return of firm $i$ on the day of alliance announcement $(\mathrm{t}=0)$ is calculated as the difference between the actual or observed return of the security on that day and the return predicted by the above equation:

$$
\mathrm{AR}_{\mathrm{i} 0}=\mathrm{R}_{\mathrm{i} 0}-\mathrm{E}\left[\mathrm{R}_{\mathrm{i} 0}\right]=\mathrm{R}_{\mathrm{i} 0}-\left(\hat{\alpha}_{\mathrm{i}}+\hat{\beta}_{i} R m_{0}\right)
$$

The market return $\left(R_{m t}\right)$ on day $t$ has been calculated from the variation in the Madrid stock exchange general index (IGBM).

In order to take into consideration possible problems of nonsynchronous (non-daily) trading in any of the securities ${ }^{\mathrm{vi}}$ making up the sample, the regression parameters are estimated using the trade-to-trade method ${ }^{\mathrm{vii}}$, an adaptation of the market model.

\subsection{Model Specification and Variable Measurement}


In order to estimate the joint influence of the variables relevant for explaining the variations seen in banks' share prices as a consequence of the announcement of an alliance, we carried out a multiple linear regression.

The dependent variable in the regression was the abnormal return obtained by the bank partner on the day of announcement $i\left(A R_{i 0}\right)$, while the variables that have been analyzed through the various hypotheses, and which appear summarized in Table 2, were the independent variables.

Thus, the cross-sectional linear model to estimate will be as follows:

$$
\begin{aligned}
& \text { AR }_{i 0}=\beta_{0}+\beta_{1} \text { RELATED }_{i}+\beta_{2} \text { FINANCIAL }_{i} \\
& +\beta_{3} \text { EXPERIENCE }_{i}+\beta_{4} \text { MISFIT }_{i}+\varepsilon_{i}
\end{aligned}
$$

With regards the first of the factors proposed, we consider that the partners of an alliance are in related businesses if all the firms participating in it are within category J: Financial Intermediation, of the CNAE viii classification (thereby applying an objective criterion for measuring the variable). Thus, the variable RELATED (related partners) takes value 1 in 146 announcements and 0 in the rest (319 announcements).

In order to analyze the relevance of the second of the proposed factors, we used information relating to the activity for which the alliance was created. If this was financial, which thereby indicates that there is a relation between the activity of the bank partner and that of the alliance, the variable FINANCIAL (financial alliance) takes value 1 (295 announcements). In the remaining cases (170 announcements) it takes value 0 .

To measure the third of the explanatory factors - the bank's previous experience in alliance management - we built the variable EXPERIENCE, which takes value 1 for each new alliance announced by the bank during the period under analysis in this present work from agreement number 6 (375 announcements) and 0 otherwise (90 announcements) ${ }^{\text {ix }}$.

The fourth and last factor allowing us to explain the excess profitability obtained by a bank's shareholders when the bank decides to participate in an alliance is the congruence between the structure chosen to govern the agreement and the characteristics of the agreement itself. Thus, the variable MISFIT have been defined as 1- $p(i, t)$ for equity alliances, and $p(i, t)$ for alliances not involving equity, where $p(i, t)$ is the estimated probability for an equity alliance, obtained by estimating a logit model, which is specified as follows:

$$
\mathrm{p}(\mathrm{i}, \mathrm{t})=\frac{e^{\beta x(i, t)}}{1+e^{\beta x(i, t)}}
$$

where $x(i, t)$ is the vector of observed characteristics of agreement $i$ in the period referred to by the announcement that enter explicitly in the model and $\beta$ a vector of unknown parameters which has to be estimated.

\begin{tabular}{|c|c|c|c|}
\hline Variable & Description & Measurement & $\mathrm{N}$ \\
\hline RELATED & $\begin{array}{c}\text { Degree of relation } \\
\text { between activities of } \\
\text { partners }\end{array}$ & $\begin{array}{l}1=\text { related partners } \\
0=\text { remaining cases }\end{array}$ & $\begin{array}{c}14 \\
6 \\
31 \\
9\end{array}$ \\
\hline $\begin{array}{l}\text { FINANCIA } \\
\text { L }\end{array}$ & Activity of alliance & $\begin{array}{c}1=\text { financial } \\
\text { alliance } \\
0=\text { remaining cases }\end{array}$ & $\begin{array}{c}29 \\
5 \\
17 \\
0\end{array}$ \\
\hline $\begin{array}{c}\text { EXPERIEN } \\
\text { CE }\end{array}$ & $\begin{array}{c}\text { Experience accumulated } \\
\text { in alliances possessed by } \\
\text { the bank }\end{array}$ & $\begin{array}{c}1=\text { for each } \\
\text { alliance, from } 6 \text { th, } \\
\text { in period of study } \\
0=\text { remaining cases }\end{array}$ & $\begin{array}{c}37 \\
5\end{array}$ \\
\hline MISFIT & $\begin{array}{l}\text { Level of misfit between } \\
\text { structure chosen and } \\
\text { characteristics of alliance }\end{array}$ & $\begin{array}{l}\mathrm{p}_{(\mathrm{i}, \mathrm{t})} \text { for non-equity } \\
\text { alliances } \\
1-\mathrm{p}_{(\mathrm{i}, \mathrm{t})} \text { for equity } \\
\text { alliances }\end{array}$ & \\
\hline
\end{tabular}

Table 2. Description and measurement of variables of linear regression model

The dependent variable of the logit model, mode of the alliance (CAPITAL), represents the form of governance chosen to cooperate. Thus, the variable CAPITAL codifies as 1 when the cooperation is formalized in a joint venture or alternatively in taking shareholdings in partners, and as 0 in the remaining cases.

In Table 3, we describe the variables included in the logistic regression model, their definition, measurement and the number of cases corresponding to each category.

The variables RELATED (related partners), FINANCIAL (financial alliance) and EXPERIENCE (previous experience in alliance management) have been defined and measured in the same way as they were for the linear regression.

To measure the field of application of the alliances (APPLICATION), we consider the possibility of the alliance containing various activities, in which case the variable takes value 1 (90 observations), or that the agreement is designed to carry out just a single activity in the value chain, in which case the variable takes value 0 ( 375 observations).

To analyze the impact of the nationality of the partners, we built the variable INTERNATIONAL, which takes value 1 for those announcements in which not all the participating partners in the alliance are domestic (159 announcements), and 0 otherwise (306 announcements).

The distinction between domestic and international alliances was measured through the variable SCOPE (scope of operations of the alliance), which takes value 1 for the 382 announcements of alliances realized for the Spanish market, and 0 if the alliance was designed to operate outside of Spain (83 cases).

And finally, to investigate the influence that the number of partners participating in the alliance has on the structure of the alliance chosen we used the variable NUMBER, which takes value 1 when the number of partners exceeds 2 (149 cases), and 0 when there are only two partners forming the alliance (316 cases). 
Table 3. Description and measurement of variables of logistic regression model

\begin{tabular}{|c|c|c|c|}
\hline Variable & Description & Measurement & $\mathrm{N}$ \\
\hline CAPITAL & $\begin{array}{l}\text { Structure adopted by } \\
\text { agreements: equity or } \\
\text { non-equity }\end{array}$ & $\begin{array}{c}1=\text { agreement } \\
\text { involves equity } \\
0=\text { remaining cases }\end{array}$ & $\begin{array}{c}14 \\
1 \\
32 \\
4\end{array}$ \\
\hline RELATED & $\begin{array}{l}\text { Degree of relationship } \\
\text { between activities of } \\
\text { partners }\end{array}$ & $\begin{array}{l}1=\text { related partners } \\
0=\text { remaining cases }\end{array}$ & $\begin{array}{c}14 \\
6 \\
31 \\
9\end{array}$ \\
\hline $\begin{array}{l}\text { APPLICATI } \\
\text { ON }\end{array}$ & $\begin{array}{c}\text { Field of application of } \\
\text { agreement }\end{array}$ & $\begin{array}{c}1=\text { multiple } \\
\text { activities } \\
0=\text { single activity }\end{array}$ & $\begin{array}{c}90 \\
37 \\
5\end{array}$ \\
\hline FINANCIAL & Activity of alliance & $\begin{array}{l}1=\text { financial alliance } \\
0=\text { remaining cases }\end{array}$ & $\begin{array}{c}29 \\
5 \\
17 \\
0\end{array}$ \\
\hline $\begin{array}{l}\text { INTERNATI } \\
\text { ONAL }\end{array}$ & $\begin{array}{l}\text { Nationality of other } \\
\text { partners participating in } \\
\text { alliance }\end{array}$ & $\begin{array}{c}1=\text { at least one } \\
\text { partner is foreign } \\
0=\text { all partners are } \\
\text { domestic }\end{array}$ & $\begin{array}{c}15 \\
9 \\
30 \\
6\end{array}$ \\
\hline SCOPE & $\begin{array}{l}\text { Scope of operations of } \\
\text { alliance }\end{array}$ & $\begin{array}{l}1=\text { alliance operates } \\
\text { exclusively in Spain } \\
0=\text { remaining cases }\end{array}$ & $\begin{array}{c}38 \\
2\end{array}$ \\
\hline $\begin{array}{c}\text { EXPERIENC } \\
\text { E }\end{array}$ & $\begin{array}{c}\text { Experience accumulated } \\
\text { in alliances possessed by } \\
\text { the bank }\end{array}$ & $\begin{array}{l}1=\text { for each alliance, } \\
\text { from } 6 \text { th, in period } \\
\text { of study } \\
0=\text { remaining cases }\end{array}$ & $\begin{array}{c}37 \\
5\end{array}$ \\
\hline NUMBER & $\begin{array}{c}\text { Agreements realized } \\
\text { between two or more } \\
\text { partners }\end{array}$ & $\begin{array}{c}1=\text { multilateral } \\
\text { alliances } \\
0=\text { bilateral alliances }\end{array}$ & $\begin{array}{c}14 \\
9 \\
31 \\
6\end{array}$ \\
\hline
\end{tabular}

\section{Results}

In Table 4 we report the results of the logistic regression model estimating the probability that given the characteristics of a particular agreement, this will be realized by means of investment in equity or not.

The overall significance of the model is given by the likelihood ratio test (LR), by means of which we test the null hypothesis that all the model coefficients, except the constant, are equal to 0 . This statistic, which follows a $\chi^{2}$ (chi-square) distribution with 7 degrees of freedom, allows us to reject the null hypothesis at a confidence level of $99 \%$. Practically all the coefficients are significantly different from 0 , except those referring to the variable EXPERIENCE and the variable referring to the presence of international partners in the agreement (INTERNATIONAL). Moreover, 83.9\% of the cases are correctly classified by the estimated model.

In view of the signs of the coefficients estimated, the probability of using minority shareholdings and joint ventures increases compared to the probability of using other governance structures closer to the market when the partners operate in related businesses, the agreement involves multiple activities, the activity of the alliance is not financial, there are more than two partners involved and the scope of activity of the alliance is outside Spain.
Table 4. Results of estimation of logistic regression model

\begin{tabular}{cc}
\hline Dependent variable & CAP \\
\hline Variables & Coefficient $^{\mathrm{b}}$ \\
Constant & $1.50^{* * *}$ \\
RELATED & $1.83^{* * *}$ \\
APPLICATION & $0.65^{*}$ \\
FINANCIAL & $-3.17^{* * *}$ \\
INTERNATIONAL & -0.20 \\
SCOPE & $-2.59^{* * *}$ \\
EXPERIENCE & 0.26 \\
NUMBER & $1.26^{* * *}$ \\
N & 465 \\
LR & $205.59^{* * *}$ \\
Percentage of cases classified \\
correctly
\end{tabular}

${ }^{\mathrm{a}} \mathrm{LR}=2 *\left(\ln \mathrm{L}\left(\hat{\beta}_{M V}\right)-\ln \mathrm{L}_{0}\right)$, where $\ln \mathrm{L}\left(\hat{\beta}_{M V}\right)$ is the natural log of the likelihood function in the estimators obtained and $\ln \mathrm{L}_{0}$ is the natural $\log$ of the likelihood function when all the coefficients of the model are made equal to 0 , except the independent term.

$\mathrm{b}^{*} \mathrm{p}<.10$.

${ }^{* * *} \mathrm{p}<.05$.

${ }^{* * *} \mathrm{p}<.01$.

These results are therefore very consistent with the postulates put forward and suggest that in the presence of attributes that raise the complexity of the transaction, equity alliances are preferred to other types of alliance.

The results of the linear regression analysis, where the abnormal returns obtained by the shareholders on day 0 are related with the explanatory variables of the hypotheses concerning the influencing factors of the value generated, are presented in Table 5.

However, before commenting on these results, we should point out that on the day of the announcement, the average revaluation experienced by the banks involved in the 465 alliance announcements which make up the sample is $0.2 \%$, a value which is statistically significant according to the statistic proposed by Brown \& Warner (1985). This result suggests therefore that, at the aggregate level, forming an alliance generates value for the shareholders of the banks. Furthermore, and similarly to the findings of the majority of studies carried out [24], the average revaluation is below $1 \%$.

With regards the results of the linear regression analysis, we should mention that in order to detect the possible existence of multicollinearity affecting the estimates obtained, we calculated the tolerance of each variable (percentage of its variance not explained by the other independent variables of the equation). The minimum value obtained is $65.9 \%$, which suggests that there are no significant problems of this type. 
Table 5. Results of estimation of linear regression models $\mathrm{s}^{\mathrm{a}}$

\begin{tabular}{ccc}
\hline & Model I & Model II \\
\hline Dependent variable & $\mathrm{AR}_{\mathrm{i} 0}(\%)$ & $\mathrm{AR}_{\mathrm{i} 0}(\%)$ \\
\hline Variables & Coefficient & Coefficient \\
Constant & -0.25 & -0.18 \\
RELATED & $0.23^{*}$ & $0.26^{*}$ \\
FINANCIAL & 0.16 & 0.11 \\
EXPERIENCE & $0.29^{* *}$ & $0.29^{* *}$ \\
MISFIT & 0.11 & \\
OVERFIT & & 0.38 \\
UNDERFIT & & $-0.56^{*}$ \\
\hline $\mathrm{N}$ & 465 & 465 \\
$\mathrm{~F}$ & $2.80^{* *}$ & $4.05^{* * *}$ \\
$\mathrm{R}^{2}$ corrected & $1.5 \%$ & $3.2 \%$ \\
\hline${ }^{*} \mathrm{p}<.10$. & & \\
${ }^{* *} \mathrm{p}<.05$. & & \\
${ }^{* * *} \mathrm{p}<.01$. & &
\end{tabular}

In the first model estimated, the explanatory variables are the degree of relation between the partners' activities, the announcing bank's previous experience in alliance management, the relation between the activities of the bank partner and those of the alliance and the level of misfit between the governance structure selected and that which would be considered appropriate according to the estimates obtained from the logit model. According to the results obtained, value generation is significantly greater when a bank announces an alliance with related partners and moreover when it possesses an important previous experience in alliance management.

The question of whether or not the activity of the alliance is largely financial does not appear to significantly influence the value generated for the bank partner. However, these results should be interpreted with caution, since although we have not detected problems of multicollinearity (according to the tolerances of the independent variables) we do observe a positive and statistically significant correlation between the variables RELATED and FINANCIAL, which may reduce the significance of the coefficients estimated in the linear regression. In fact, if only one of these 2 variables is included in the regression, the respective coefficients of both become positive and statistically significant.

Finally, the variable measuring the presence of a possible selection error in the governance structure is not statistically significant. However, the error in the selection of the alliance governance form can occur in 2 directions. In some cases we can speak of governance overfit, if too many hierarchical elements are introduced to manage relatively uncomplicated transactions - i.e., a joint venture or participation in the equity is preferred to develop cooperation agreements which according to their characteristics could be more efficiently governed using structures closer to the market. In other cases, the deficient fit can be an underfit if non-equity alliances are chosen to manage relatively complex transactions, when it would probably be more appropriate to use an equity agreement.

Thus, in Model 2, the variable MISFIT is replaced by 2 new variables. The variable $O V E R F I T$ is calculated as $1-p_{(i, t)}$ for equity alliances and 0 for the others, while the variable UNDERFIT takes value $p_{(i, t)}$ for non-equity alliances and 0 otherwise.

Although the coefficients of the RELATED and EXPERIENCE explanatory variables remain statistically significant, disaggregating the variable that measures the error in the choice of the governance structure into the two variables mentioned above allows us to identify a negative and statistically significant effect of the variable UNDERFIT, which is moreover strong. Thus, it seems that the stock market perceives with concern an announcement where alliance partners use relatively non-hierarchized governance structures despite high levels of transaction complexity, and hence reacts negatively in such cases. In contrast, an overfit i.e., the use of equity agreements for governing relatively simple transactions - does not appear to be penalized by the market.

\section{Conclusions}

In the present work, we consider the question of whether the differential benefits obtained by firms when they participate in alliances depend on the conditions under which these are realized. Specifically: the strategic positioning of the partners within the alliance and $v i s-\grave{a}$-vis the alliance, the experience the partners have managing alliances and the degree of fit between the structure governing the agreement and the characteristics of the transaction.

With this objective, we proposed four hypotheses, one for each of the factors determining value creation in alliances, whose theoretical foundations are found in the opportunity that cooperation between firms offers for reaping synergies or increasing market power, as well as in transaction cost economics.

The hypothesis testing was carried out using a sample made up of 465 alliance announcements by listed Spanish banks in a period when alliances were profusely used (1996-1999) given the imminent start of European Monetary Union.

We should first point out that using the event study methodology we have obtained a positive and significant average abnormal return on the day of the announcement, which suggests that at the aggregate level combining resources and capabilities with those of other firms in alliances allows Spanish banks to improve efficiency and generate the desired synergies and/or market power. Hence the result of alliance formation is clearly positive.

In addition, and with respect to the hypotheses formulated, we observe that it is those agreements formed with related partners and where the announcing bank possesses significant experience which generate most value. However, and with regards the degree of relation between the activities 
of the partner and those of the alliance, we find that alliances of a financial nature, controlling for the other factors, are not perceived differently by the investors.

Thus, combining related resources is more effective for the listed Spanish banks than participating in projects with partners among which there are important asymmetries, regardless of the activity for which the alliance is designed. In addition, given that learning by experience occurs when the firm is able to internalize that knowledge, the positive response that has been observed in the market to the fact that the bank has experience in alliance formation should be interpreted as the expectation that as a result of the learning the firm will have a new strength, which will allow it to achieve more benefits from the cooperation than it would be able to if it had less experience in the use of these organizational formulae.

Finally, and with regards the influence of the potentially inappropriate choice of alliance governance structure on value creation, we only see a significant impact when we differentiate between the overfit and the underfit in the use of hierarchical elements. This division implies that the bank's shareholders appear to perceive a substantial risk for the achievement of the objectives of the alliance when this incorporates less hierarchical elements than it should do $a$ priori, given the characteristics of the agreement. The introduction of hierarchical controls allows firms to reduce transaction costs in the presence of many interdependencies between the partners and complexity in the transaction. Thus, the lack of these controls increases the risk that opportunistic behaviors appear and that the firm fails to capture the desired knowledge from a partner.

In short, our findings provide a series of guidelines that allow us to determine which characteristics of the alliance or the partners are most valued by the market. We should stress, however, that the results should be interpreted with caution given the limitations of the work. The first limitation is that the results obtained may be difficult to extrapolate to other periods different from the one analyzed, or to other sectors of activity. A second limitation is that the study has focused only on one group of key variables identified by the literature as generators of efficiency, synergies or market power. However, other factors we have not considered in the present work undoubtedly also influence value creation, making it important to postulate new factors determining value creation and allowing us to increase the significance of the results obtained.

\section{Acknowledgements}

We acknowledge financial support from the Spanish Ministry of Economy and Competitiveness MINECO and FEDER (project eco2012-36290-c03-01) and from the DGA-FSE through the Consolidated Groups COMPETE and CREVALOR.

\section{REFERENCES}

[1] S. Balakrishnan, M. Koza. Information Asymmetry, Adverse Selection and Joint Ventures. Journal of Economic Behavior and Organization, 20: 99-117, 1993.

[2] J. Koh, N. Venkatraman. Joint Venture formations and stock market reactions: an assessment in the information technology sector. Academy of Management Journal, 34: 869-892, 1991.

[3] J. McConnell, J. Nantell. Common Stock Returns and Corporate Combinations: The Case of Joint Ventures. Journal of Finance, 40: 519-536, 1985.

[4] A. Madhok, S.B. Tallman. Resources, Transactions and Rents: Managing Value Through Interfirm Collaborative Relationships. Organization Science, 9(3), May-June: 326-339, 1998.

[5] S.H. Chan, J.W. Kensinger, A.J. Keown, J.D. Martin. Do strategic alliances create value?. Journal of Financial Economic, 46: 199-221, 1997.

[6] H. Chen, M.Y. Hu, J. Shieh, The wealth effect of international joint ventures: the case of U.S. investment in China. Financial Management, winter: 31-41, 1991.

[7] S.S. Chen, K.W. Ho, C. Lee, G.H. Yeo. Investment opportunities, free cash flow and market reaction to international joint ventures. Journal of Banking and Finance, 24: 1747-1765, 2000.

[8] C. Crutchley, E. Guo, R. Hansen. Stockholder Benefits from Japanese-U.S. Joint Ventures. Financial Management, winter: 22-30, 1991.

[9] S. Das, P. Sen, S. Sengupta. Impact of Strategic Alliances on Firm Valuation. Academy of Management Journal, 41(1): 27-41, 1998.

[10] J.J. Reuer, M.P. Koza. Asymmetric information and joint venture performance: Theory and evidence for domestic and international joint ventures. Strategic Management Journal, 21: 81-88, 2000.

[11] J.R. Woolridge, C.C. Snow. Stock Market Reaction to Strategic Investment Decisions. Strategic Management Journal, 11: 353-363, 1990.

[12] B.N. Anand, T. Khanna. Do firms learn to create value? The case of alliances. Strategic Management Journal, 21: 295-315, 2000.

[13] P. Kale, J.H. Dyer, H. Singh. Alliance capability, stock market response, and long-term alliance success: the role of the alliance function. Strategic Management Journal, 23: 747-767, 2002.

[14] S. Park, D. Kim. Market Valuation of Joint Ventures: Joint Venture Characteristics and Wealth Gains. Journal of Business Venturing, 12: 83-108, 1997.

[15] O.E. Williamson. Comparative economic organization. The analysis of Discrete Structural Alternatives. Administrative Science Quarterly, 36: 269-296, 1991.

[16] R. Gulati. Does Familiarity Breed Trust? The Implications of repeated Ties for Contractual Choice in Alliances. Academy of Management Journal, 38(1): 85-112, 1995.

[17] G.P. Pisano. Using equity participation to support 
exchange: Evidence from the biotechnology industry. Journal of Law, Economics and Organization 5 1: 109-126, 1989.

[18] J.E. Oxley. Appropriability Hazards and Governance in Strategic Alliances: A Transaction Cost Approach. The Journal of Law, Economics \& Organization, 13(2): 387-409, 1997.

[19] R.C. Sampson. The cost of misaligned governance in R\&D alliances. Journal of Law Economics and Organization, 20: 484-526, 2004.

[20] V. Salas. Acuerdos de cooperación entre empresas: bases teóricas. Economía Industrial, 266: 47-60, 1989.

[21] A. Jacquemin. La Nueva Organización Industrial: Fuerzas de mercado y comportamiento estratégico. Barcelona: Vicens-Vives, 1989

[22] F. Sachwald. Cooperative Agreements and the Theory of the Firm: focusing on Barriers to Change. Journal of Economic Behavior \& Organization, 35: 203-225, 1998.

[23] I. Ansoff. Corporate Strategy. New York, NY: McGraw-Hill, 1965.

[24] H. Merchant, D. Schendel. How do International Joint Ventures Create Shareholder Value?. Strategic Management Journal, 21: 723-737, 2000.

[25] O.E. Williamson. Markets and Hierarchies: Analysis and Antitrust Implications. New York: The Free Press, 1975.

[26] M. Porter, M. Fuller. Coalitions and Global Strategy. In Porter, M. (Eds.), Competition in Global Industries: 315-344. Boston: Harvard Business School Press, 1988.

[27] W.M. Cohen, D.A. Levinthal. Absorptive Capacity: A New Perspective on Learning. Administrative Science Quarterly, 35: 128-152, 1990.

[28] J.H. Dyer, H. Singh. The relational view: cooperative strategy and sources of interorganizational competitive advantage. Academy of Management Review, 23(4): 660-679, 1998 .

[29] M. Polanyi. The tacit dimension. New York: Deubleday, 1967.

[30] S.G. Winter. Knowledge and Competence as Strategic Assets. In D.J. Teece (Eds.), the Competitive Challenge: 159-184. Berkeley, CA: Harper and Row, 1987.

[31] D.E Westney. Domestic and Foreign Learning Curves in Managing International Cooperative Strategies. In F.J. Contractor and Lorange (Eds.), Cooperative Strategies in International Business: 339-346. Lexington, MA: Lexington Books, 1988.

[32] M.A. Lyles. Learning among Joint Venture Sphisticated Firms. In F.J. Contractor and P. Lorange [eds.]: Cooperative Strategies in International Business: 302-315. Lexington, MA: Lexington Books, 1988.

[33] M. Granovetter. Economic action and social structure: a theory of embeddedness. American Journal of Sociology, 91: 481-510, 1985.

[34] O.E. Williamson. Calculativeness, trust, and economic organization. Journal of Law and Economics, 36: 453-486, 1993.
[35] A. Ariño, J. de la Torre. Learning from failure: towards and evolutionary model of collaborative ventures. Organization Science, 93: 306-325, 1998.

[36] J. Rialp, V. Salas. La colaboración empresarial desde la teoría de los Derechos de Propiedad. Investigaciones Económicas, XXVI(1): 113-144, 2002.

[37] F.K. Contractor, P. Lorange. Why Should Firms Cooperate? The Strategy of Economics Basis for Cooperative Ventures. In F.J. Contractor \& P. Lorange (Eds.), Cooperative Strategies in International Business: 3-30. Lexington Books, 1988.

[38] K.R. Harrigan. Managing for Joint Ventures Success. Lexington, MA: Lexington Books, 1986.

[39] J.E. Oxley. Institutional environment and the mechanisms of governance: the impact of intellectual property protection on the structure of inter-firm alliances. Journal of Economic Behavior \& Organization, 38: 283-309, 1999.

[40] O.E. Williamson. The Economic Institutions of Capitalism. New York: The Free Press, 1985.

[41] J.F. Hennart. The Transaction Costs Theory of Joint Ventures: An empirical study of Japanese subsidiaries in the US. Management Science, 37(4): 483-497, 1991.

[42] J.F. Hennart. A Transaction Costs Theory of Equity Joint Ventures. Strategic Management Journal, 9(4): 361-374, 1988.

[43] P. Mariti, R. Smiley. Co-operative agreements and the organization of industry. The Journal of Industrial Economics, 31(4): 437-451, 1983.

[44] J. Hagedoorn. Understanding the rationale of strategic technology partnering: Inter-organizational modes of cooperation and sectorial differences. Strategic Management Journal 14(5): 371-386, 1993.

[45] J.J. Reuer, A. Ariño. Contractual Renegotiations in Strategic Alliances. Journal of Management, 28(1): 47-68, 2002

[46] W.F. Sharpe. Capital Asset Prices: A Theory of Market Equilibrium under Conditions of Risk. Journal of Finance, 19(3): 425-442, 1964

[47] S.E. Boyle. An estimate of the number and size distribution of domestic joint subsidiaries. Antitrust Law and Economics Review, 1: 81-92, 1968

[48] P.R. Dixon. Joint Ventures: What is their impact on competition?. Antitrust Bulletin, 7: 397-410, 1962.

[49] W.J. Mead. The competitive significance of joint ventures. Antitrust Bulletin, 12: 819-849, 1967.

[50] O. Hart. Firms, Contracts, and Financial Structure. Oxford: Claredon Press, 1995.

[51] S.J. Brown, J.B. Warner. Using daily stock returns: The case of event studies. Journal of Financial Economics, 14: 3-31, 1985 .

[52] E. Dimson, P.R. Marsh. Event study methodologies and the size effect. The case of U.K. Press Recommendations. Journal of Financial Economics, 17:113-142, 1986.

[53] P.R. Marsh. Equity rights issues and the efficiency of the 
UK stock market. Journal of Finance, 34: 839-862, 1979.

[54] M.S. Scholes, J.T. Williams. Estimating betas from nonsynchronous data. Journal of financial Economics 5: 309-328, 1977.

[55] E. Dimson. Risk measurement when shares are subject to infrequent trading. Journal of Financial Economics, 7: 197-226, 1979.

[56] K.J. Cohen, G.A. Hawawini, S.F. Maier, R.A. Schwartz, D.J. Whitcomb. Frictions in the trading process and the estimation systematic risk. Journal of Financial Economics, 12: 263-278, 1983.

\section{Endnotes}

${ }^{\mathrm{i}}$ In fact, the first work in this discipline analyzing the implications of cooperation compared to competition $[47,48,49]$ made it clear that one of the main motives for establishing agreements is to favor measures restricting competition.

ii Of the various perspectives from which authors have analyzed experience
competition. in the use of alliances as a determining factor in value creation, we refer to only one of them in this current work - that which considers that there is a learning effect due to having previously managed alliances. In this case, the firm is the unit of analysis and firm experience is investigated considering the total number of alliances realized [12].

iii In transactions, when specific human capital that has previously been accumulated is involved, the joint ownership of the non-human assets is inefficient compared to separate ownership [50].

iv Although we refer to securities for simplicity, what we mean by security $i$

is in fact announcement $i$, regardless of which bank this is. That is, the subscript $i$ does not refer to a specific bank (bank $i$ ) but rather to a specific announcement (announcement $i$ ), since this is our unit of analysis. Thus, $\mathrm{i}=1,2, \ldots 465$.

$\mathrm{v}$ To estimate the parameters of the market model, for each announcement we used the daily returns of the bank participating in the alliance corresponding to the interval $[-200,-21]$, where $t=0$ is the day of the announcement. Thus, the 21 days prior to the announcement of the event are excluded as model parameters in case share prices are already affected by the event during this period and partially incorporate its effect [51].

${ }^{\mathrm{vi}}$ We were obliged to apply the technique of event study methodology with nonsynchronous trading in the case of three banks in order to obtain the abnormal return associated with each of the events and thereby incorporate these announcements in our sample. We opted to apply nonsynchronous trading with the banks Herrero, Simeón and Commerzbank, since they have a percentage of trading days during the period of study below $76 \%$ on average, clearly inferior to the other banks making up the sample, whose percentage of trading days is in general more than $99 \%$.

vii Various event studies use this method [52,53]. However, there are alternative methods measuring the systematic risk when share prices suffer from nonsynchronous trading, such as that of Scholes-Williams [54], Dimson [55] aggregate coefficients (DAC) and the extension of the work of Scholes-Williams (SW) proposed by Cohen et al. [56].

viii Spanish standard classification of economic activity.

ix According to the various tests carried out, until the banks have participated in their 5th alliance, there is no significant difference compared to banks with less experience. The variable is built taking this into account. 